\title{
Identification of Salt-Tolerant Sinorhizobium sp. Strain BL3 Membrane Proteins Based on Proteomics
}

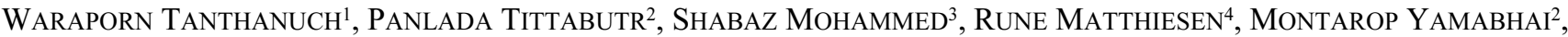 \\ Monchai Manassila ${ }^{2}$, Ole NoerregaArd Jensen ${ }^{5}$, NANTAKorn BoOnKerD ${ }^{2}$, and NeUng TEAUMroOnG ${ }^{2 *}$ \\ ${ }^{1}$ Synchrotron Light Research Institute (Public Organization), Suranaree, Muang, Nakhon Ratchasima, 30000, Thailand; \\ ${ }^{2}$ School of Biotechnology, Institute of Agricultural Technology, Suranaree University of Technology, Suranaree, Muang, \\ Nakhon Ratchasima 30000, Thailand; ${ }^{3}$ Biomolecular Mass Spectrometry and Proteomics Group, Bijvoet Center for \\ Biomolecular Research and Utrecht Institute for Pharmaceutical Sciences, Utrecht University, Utrecht, The Netherlands; \\ ${ }^{4}$ Bioinformatics Unit-CIC bioGUNE, Parque Tecnológico de Bizkaia Edificio 801 A, 48160 Derio, Spain; and ${ }^{5}$ Department \\ of Biochemistry and Molecular Biology, University of Southern Denmark, Campusvej 55, DK-5230, Odense M, Denmark
}

(Received December 20, 2009-Accepted July 3, 2010—Published online July 24, 2010)

Sinorhizobium sp. BL3 is a salt-tolerant strain that can fix atmospheric nitrogen in symbiosis with leguminous host plants under salt-stress conditions. Since cell membranes are the first barrier to environmental change, it is interesting to explore the membrane proteins within this protective barrier under salt stress. The protein contents of membraneenriched fractions obtained from BL3 were analyzed by nanoflow liquid chromatography interfaced with electrospray ionization tandem mass spectrometry. A total of 105 membrane proteins were identified. These proteins could be classified into 17 functional categories, the two biggest of which were energy production and conversion, and proteins not in clusters of orthologous groups (COGs). In addition, a comparative analysis of membrane proteins between salt-stressed and non-stressed BL3 cells was conducted using a membrane enrichment method and off-line SCX fractionation coupled to nanoLC-MS/MS. These techniques would be useful for further comparative analysis of membrane proteins that function in the response to environmental stress.

Key words: Sinorhizobium sp., membrane proteome analysis, mass tag, salt stress, strong cationic micro-columns

Salinity is one of the environmental factors that adversely affects Rhizobium-legume symbiosis at all stages of the Rhizobium-legume interaction. Salt stress causes a reduction in the number of rhizobia attached to root hairs and a decrease in active $\mathrm{N}_{2}$-fixing nodules (38). The mechanisms involved in cell adaptation or survival under salt stress have been intensively studied. In salt stressed cells, the outer membrane proteins provide an interface with the surrounding environment. Moreover, membrane proteins play an important role in maintaining cell volume and the intracellular ion balance (33), the transportation of nutrients to and from the cell (19), conjugation (21), controlling cell morphology (36), intercellular communication, and cell metabolism (37). Several rhizobial membrane proteins have been reported to respond to salt stress, including a glycine betaine/proline betaine transporter encoded by bet $S$ (5), a potassium uptake system protein encoded by kup (29), and an outer membrane lipoprotein encoded by omp10 (40). At present, large scale expression profiling of membrane proteins is well established. The first insight in a global study of gene expression under salt stress in Sinorhizobium meliloti was reported by Ruberg et al. (35), using the transcriptomic approach that allows a comprehensive global analysis at the mRNA level. Fifteen genes involved in ion uptake were down-regulated, and 14 genes involved in the transport of small molecules were up-regulated. Nevertheless, a number of experimental and computational studies have suggested that information

\footnotetext{
* Corresponding author. E-mail: neung@sut.ac.th.;
}

Tel: +66-44-224279; Fax: +66-44-216345. on gene expression should be complemented by protein expression data to adequately describe and model cellular metabolism (16). Therefore, it is necessary to perform a proteomic analysis, especially at the membrane level, to confirm the transciptomic data, since mRNA levels are not always representative of protein expression levels (15).

A membrane proteomic analysis is considered highly challenging due to the extreme physicochemical properties of membrane proteins. Two-dimensional gel electrophoresis (2-DE) enables the analysis of membrane proteins when special precautions are taken (37). Analyses using 2-DE have identified 37 membrane proteins from Escherichia coli (26), 23 from Salmonella enterica subsp. enterica (previous S. typhimurium) (28), 14 from Klebsiella pneumoniae (27), and 15 from green-sulfur bacterium Chlorobium tepidum (1). Using sodium dodecyl sulfate polyacrylamide gel electrophoresis (SDS-PAGE) in combination with liquid chromatography-tandem mass spectrometry (LC-MS/MS), 114 integral membrane proteins were identified in Halobacterium salinarum (20) and 79 membrane proteins were detected in Mycobacterium tuberculosis (14). Emerging gelfree proteomic approaches have provided powerful tools for the analysis of complex mixtures and have made membrane proteins accessible for mass spectrometric proteomic analysis (43). With online 2-dimensional liquid chromatographytandem mass spectrometry (2D-LC-MS/MS), 333 membrane proteins were obtained from Pseudomonas aeruginosa (4) and 248 from M. tuberculosis (25).

In this present study, we conducted an intensive analysis of membrane proteins of salt-tolerant Sinorhizobium sp. 
BL3 and comparative analysis of membrane proteins under salt stress based on the detection of labeled peptides. The use of an amine-reactive stable isotope labeling reagent (Lystag) with off-line strong cationic micro-columns (SCX) and nanoflow liquid chromatography/tandem mass spectrometry ( $\eta \mathrm{LC}-\mathrm{MS} / \mathrm{MS}$ ) allowed the initial identification of microbial membrane proteins changing in response to different conditions.

\section{Materials and Methods}

\section{Sinorhizobium sp. BL3 cultivation}

The inoculum of Sinorhizobium sp. BL3 was grown aerobically at $28^{\circ} \mathrm{C}$ in yeast extract mannitol (YEM) medium (40) containing (g L $\left.{ }^{-1}\right): \mathrm{MgSO}_{4} \cdot 7 \mathrm{H}_{2} \mathrm{O}, 0.2 ; \mathrm{K}_{2} \mathrm{HPO}_{4}, 0.5 ;$ mannitol, 10 ; yeast extract, $0.5 ; \mathrm{NaCl}, 0.1$. The $\mathrm{pH}$ was maintained at $6.5-6.8$. These cultures of mid-log-phase cells were then used as the $10 \%$ inoculum for $1 \mathrm{~L}$ production cultures.

The production culture of Sinorhizobium sp. BL3 was grown in modified minimal salts medium (17), which contained $\left(\mathrm{mg} \mathrm{L}^{-1}\right)$ $\mathrm{Na}_{2} \mathrm{SO}_{4}, 100 ; \mathrm{MgSO}_{4} \cdot 7 \mathrm{H}_{2} \mathrm{O}, 200 ; \mathrm{CaCl}_{2} \cdot 2 \mathrm{H}_{2} \mathrm{O}, 5 ; \mathrm{MnSO}_{4} \cdot 4 \mathrm{H}_{2} \mathrm{O}$, $1.11 ; \mathrm{K}_{2} \mathrm{HPO}_{4}, 4.35 ; \mathrm{KH}_{2} \mathrm{PO}_{4}, 3.4 ; \mathrm{ZnSO}_{4} \cdot 7 \mathrm{H}_{2} \mathrm{O}, 1 ; \mathrm{CuSO}_{4} \cdot 5 \mathrm{H}_{2} \mathrm{O}$, $0.5 ; \mathrm{FeSO}_{4} \cdot 7 \mathrm{H}_{2} \mathrm{O}, 5$; NaEDTA, 1 ; thiamine $\mathrm{HCl}, 1$; pantothenic acid, 1; biotin, $2 \times 10^{-3}$. Carbon and nitrogen sources were added $\left(\mathrm{g} \mathrm{L}^{-1}\right)$ as sodium glutamate, 2.5; sodium succinate, 2.0; and $\mathrm{KNO}_{3}$, 0.05 . Media were supplemented with streptomycin $(\mathrm{Sm})$ at a final concentration of $100 \mu \mathrm{g} \mathrm{mL}^{-1}$.

\section{Preparation of bacterial membrane fractions}

Sinorhizobium sp. BL3 cells from $1 \mathrm{~L}$ of cell culture in minimal growth medium were used for each independent experiment (with or without salt). For the salt stress condition, cell cultures were grown to reach $\mathrm{OD}_{600}$ of 0.6 , and sodium chloride $(\mathrm{NaCl})$ solution was then added to create a final concentration of 0.4 or $0.5 \mathrm{M}$ in the media. Cells were further cultured for $1 \mathrm{~h}$ or $6 \mathrm{~h}$ before harvesting. For the control treatment, cells were cultured in the same conditions but without sodium chloride. Cells derived from $1 \mathrm{~L}$ of culture were collected by centrifugation at $7,000 \times g$ at $4^{\circ} \mathrm{C}$ and passing twice with ice-cold $10 \mathrm{mM}$ Tris-HCl, $\mathrm{pH}$ 7.5. The cell pellet was resuspended in $10 \mathrm{~mL}$ of ice-cold $10 \mathrm{mM}$ Tris- $\mathrm{HCl}, \mathrm{pH} 7.5$ containing $1 \mathrm{mM}$ phenylmethylsulphonyl fluoride (PMSF) and disrupted by passage through an Aminco French press at 1,200 psi twice. The lysate was centrifuged twice at $7,000 \times \mathrm{g}$ for $10 \mathrm{~min}$ at $4^{\circ} \mathrm{C}$ to remove unbroken cells. Membrane protein extraction was performed according to Molloy et al. $(26,27)$. Briefly, the supernatant was diluted with ice-cold $0.1 \mathrm{M}$ sodium carbonate $(\mathrm{pH} 11)$ to a final volume of $60 \mathrm{~mL}$ and then stirred slowly on ice for $1 \mathrm{~h}$. The carbonate-treated membranes were collected by ultracentrifugation in a Sorval $55.2 \mathrm{Ti}$ rotor at an average of $100,000 \times \mathrm{g}$ for $1.5 \mathrm{~h}$ at $4^{\circ} \mathrm{C}$. The membrane pellet was washed twice by sonication in $5 \mathrm{~mL}$ of $10 \mathrm{mM}$ Tris- $\mathrm{HCl}, \mathrm{pH} 7.5$, containing $1 \mathrm{mM}$ PMSF and centrifuged at $4^{\circ} \mathrm{C}, 14,000 \times g$ for $30 \mathrm{~min}$ in an Eppendorf table centrifuge. The membrane pellet was then solubilized in $1 \mathrm{~mL}$ of a $9 \mathrm{M}$ urea solution and centrifuged at $14,000 \times g$ for $30 \mathrm{~min}$ at $4^{\circ} \mathrm{C}$. The solubilized membrane proteins were diluted to a final urea concentration of $8 \mathrm{M}$. Then, the protein concentration was measured by the Bradford method (6), with bovine serum albumin used for calibration.

\section{In-solution digestion of membrane proteins}

The soluble membrane proteins $(10 \mathrm{mg})$ were resuspended in 21 $\mu \mathrm{L}$ of $400 \mathrm{mM} \mathrm{NH} \mathrm{HCO}_{3}(\mathrm{pH}$ 7.8) (Fisher Scientific, Pittsburgh, PA, USA) in a $8 \mathrm{M}$ urea solution (Fisher Scientific), and dithiothreitol (Sigma-Aldrich, St Louis, MO, USA) was added to create a final concentration of $45 \mathrm{mM}$. The solution was then incubated for $15 \mathrm{~min}$ at $56^{\circ} \mathrm{C}$. Subsequently, it was chilled, $5 \mu \mathrm{L}$ of iodoacetamide $(100 \mathrm{mM})$ was added, and incubation continued in the dark at room temperature for $15 \mathrm{~min}$. Lys C protease (Calbiochem, San Diego, CA, USA) was added (15 ng) and the mixture further incubated at $37^{\circ} \mathrm{C}$ for $6 \mathrm{~h}$. The proteolyzed mixture was diluted by the addition of $140 \mu \mathrm{L}$ of $\mathrm{H}_{2} \mathrm{O}$, and then $5 \mu \mathrm{L}$ of $20 \mathrm{pM}$ sequence grade trypsin (Promega, Madison, WI, USA) was added and the resulting solution was incubated overnight at $37^{\circ} \mathrm{C}$.

\section{Chemical derivatization of membrane peptides for quantitative analysis}

The digested membrane proteins $(2 \mu \mathrm{g})$ were dried in vacuo using a SpeedVac (Thermo Savant, Waltham, MA, USA). The dried peptides from the control condition (no $\mathrm{NaCl}$ added into culture media) were derivatized with $40 \mu \mathrm{L}$ of a solution containing a light reagent $\left(\left(\mathrm{d}_{0}\right)\right.$ 2-methoxy-4,5-dihydro- $1 H$-imidazole $\left.(1 \mathrm{M})\right)$, while the peptides from the four salt stress conditions (corresponding to 0.4 or $0.5 \mathrm{M} \mathrm{NaCl}$, at 1 or $6 \mathrm{~h}$ exposure) were added to a heavy reagent $\left(\left(\mathrm{d}_{4}\right)\right.$ 2-methoxy-4,5-dideutero-1 $H$-imidazole)) (Sigma-Aldrich). Each reaction mixture was mixed well and the reaction was allowed to proceed for $3 \mathrm{~h}$ at $55^{\circ} \mathrm{C}$. An equal volume of $5 \%$ formic acid (Fisher Scientific) was added to quench the reaction followed by pipetting of the control reaction into each salt stress reaction. The mixed reaction was de-salted using micro-columns as described by Rappsillber et al. (34). The reaction consisted of four sets and was analyzed in duplicate using different samples.

\section{Separation of peptides by strong cation exchange chromatography}

Strong cation exchange (SCX) chromatography was performed using a micro column packed with Self Pack POROS 20S (Applied Biosystems, Framingham, MA, USA) in a Gelloader tip as described in Gobom et al. (13). SCX columns were conditioned by washing 4 times with $20 \mu \mathrm{L}$ of $30 \%$ acetonitrile, ammonium formate $\left(\mathrm{NH}_{4} \mathrm{FA}\right)(1 \mathrm{M}, \mathrm{pH} 3)$ (Fisher Scientific). The tryptic peptides were dissolved in $30 \%$ acetonitrile, $\mathrm{NH}_{4} \mathrm{FA}(1 \mathrm{M}, \mathrm{pH} 3)$ and loaded onto the SCX-packed column. The flow-through was collected. A step-wise elution was performed using $20 \mu \mathrm{L}$ of $30 \%$ acetonitrile in different concentrations of $\mathrm{NH}_{4} \mathrm{FA}(20,30,40,50,60$ and $120 \mathrm{mM}$, $\mathrm{pH} 3$ ). All fractions were dried in vacuo and resuspended in $5 \%$ formic acid to allow analysis by nanoLC-MS/MS.

\section{Peptide mass fingerprinting}

Peptide mass fingerprinting (PMF) was performed by matrixassisted laser desorption ionization-time of flight mass spectrometry (MALDI-TOF MS). Samples were desalted and concentrated with self packed C18-columns as described by Gobom et al. (13). Peptides were eluted in a volume of $0.5 \mu \mathrm{L}$ using a concentrated solution of $\alpha$-cyano-4-hydroxycinnamic acid ( $\alpha$-CHCA) in $70 \%$ acetonitrile and $0.1 \%$ trifluoroacetic acid in water, and deposited directly onto the MALDI plate. A tryptic digest of $\beta$-lactoglobulin was used for the external calibration. The analysis was performed on a Bruker ultraflex MALDI-TOF-TOF mass spectrometer (Bruker Daltonik $\mathrm{GmbH}$, Bremen, Germany) in the positive ion mode. The MALDIgenerated ions were extracted and then accelerated to $25 \mathrm{kV}$. The time of flight (TOF) was operated in the reflectron mode.

\section{Separation of peptides by nanoflow liquid chromatography}

Automated nanoflow liquid chromatography/tandem mass spectrometry was performed using a Q-TOF Ultima mass spectrometer (Waters/Micromass UK, Manchester, UK) employing automated data-dependent acquisition (DDA). A nanoflow-HPLC system (Ultimate; Switchos2; Famos; LC Packings, Amsterdam, Netherland) was used to deliver a flow rate of $2 \mu \mathrm{L} \mathrm{min}-1$ (loading) and $100 \mathrm{~nL} \mathrm{m^{-1 }}$ (elution) onto a homemade $2 \mathrm{~cm}$ fused silica precolumn (75- $\mu \mathrm{m}$ inner diameter (i.d.); 375- $\mu \mathrm{m}$ outer diameter. (o.d.); Reprosil C18-AQ, $3 \mu \mathrm{m}$ (Ammerbuch-Entringen, Tübingen, Germany)) using an autosampler. Sequential elution of peptides was accomplished by using a linear gradient from solution A $(0.6 \%$ acetic acid) to $40 \%$ of solution B $(80 \%$ acetonitrile, $0.5 \%$ acetic acid) in 90 min over the precolumn in-line with a homemade 15-20 $\mathrm{cm}$ resolving column (50- $\mu \mathrm{m}$ i.d.; $375-\mu \mathrm{m}$ o.d.; Resprosil C18-AQ, $3 \mu \mathrm{m}$ (Ammerbuch-Entringen)). The resolving column was connected using a fused silica transfer line $(20-\mu \mathrm{m}$ i.d.) to a distally 
coated fused silica emitter (New Objective, Cambridge, MA, USA) (360- $\mu \mathrm{m}$ o.d. $/ 20-\mu \mathrm{m}$ i.d./10 $\mu \mathrm{m}$-tip i.d.) biased to $1.8 \mathrm{kV}$.

The mass spectrometer was operated in the positive ion mode with a resolution of 9,000-11,000 full-width half-maximum (FWHM), using a source temperature of $80^{\circ} \mathrm{C}$ and a counter current nitrogen flow rate of $150 \mathrm{~L} \mathrm{~h}^{-1}$. Data-dependent analysis was employed (the five most abundant ions in each cycle were subjected to MS/MS): 1 second MS (m/z 350-1500) and 5×1 second MS/MS (m/z 50-2000, continuum mode), 30 seconds dynamic exclusion. A charge state recognition algorithm was employed to determine the optimal collision energy for low energy CID MS/MS of peptide ions. External mass calibration using sodium iodide (NaI) resulted in mass errors of less than $50 \mathrm{ppm}$, typically $5-15 \mathrm{ppm}$ in the $\mathrm{m} / \mathrm{z}$ range 50-2000. Raw data were processed using ProteinLynx Global Server ProteinLynx 2.0.5 (smooth 5/3 Savitzky Golay and center 4 channels $/ 80 \%$ centroid) and the resulting MS/MS data sets were exported in the Micromass.pkl format.

\section{Computational analysis}

The raw data were processed using the fast de-convolution algorithm in Protein Lynx Global Server v 2.0.5 (Waters/Micromass UK). The resulting pkl files were imported into Mascot v. 2.0 (Matrix Sciences, London, UK) and VEMS v3.0 (24) (http://yass. sdu.dk/) for database-dependent searching of the S. meliloti 1021 protein sequence database (http://genome.kazusa.or.jp/rhizobase/ Sinorhizobium/genes.faa).

The ExRaw.exe which is a part of the VEMS v3.0 package was used to automatically extract the retention times and original charge state of fragment ions of each MS/MS spectrum from the raw data into the pkl file output, and imported into VEMS for the quantitative analysis. The mass accuracy used in the quantitation was 0.3 Da. The threshold score on peptides was set to the default significance threshold $(P<0.05)$, and the minimum number of quantified peptides necessary for protein quantitation was set to 1 . This threshold value was selected based on previous experience. The parameters for protein quantitation with the VEMS software were set to allow a maximum standard deviation of $7 \%$. However, the expression change level was considered manually again of the quantitative peptides exhibiting less than 5\% standard deviation. All low confident identifications and quantifications were manually validated using the visual tools in the VEMS program. The quantitative score represented the degree of expression change which was calculated by dividing the integrated intensity of the masses of the heavy version of the peptide with the total integrated intensity of heavy and light peptides and multiplying by 100 . This means that a quantitation value less than $40 \%$ (reduce 1.5 folds) corresponds to down regulation, while over $60 \%$ (induce 1.5 folds) represents up regulation. Functional categorization was accessed by RhizoBase/ Sinorhizobium meliloti 1021 website (http://genome.kazusa.or.jp/ rhizobase/Sinorhizobium/genes/category.txt). The predicted transmembrane domains (TMDs) were searched using TopPred (http:// mobyle.pasteur.fr/cgi-bin/portal.py?form=toppred) (10), TMHMM 2.0 (http://www.cbs.dtu.dk/services/TMHMM/ (24), and SPOCTOPUS (http://octopus.cbr.su.se/index.php) (41). N-terminal signal peptide predictions were based on a combination of several artificial neural networks and hidden Markov models by SignalP 3.0. (http:// www.cbs.dtu.dk/services/SignalP/) (3). Protein localization was searched by PSORTb version 3.0.0 (http://www.psort.org/psortb/) (12), and Localizome (http://localodom.kobic.re.kr/LocaloDom/ index.htm (23).

\section{Results and Discussion}

Identification of proteins in the Sinorhizobium sp. BL3 membrane-enriched fraction by $L C-M S / M S$

Previously (30), Sinorhizobium sp. strain BL3 was proved to tolerate up to $600 \mathrm{mM} \mathrm{NaCl}$ and to be effective in at fixing $\mathrm{N}_{2}$. The 16S rRNA gene sequence of Sinorhizobium sp. BL3 showed $98 \%$ similarity to the sequence of S. meliloti 1021 . All separable six peptide fractions from SCX micro columns were injected into the $\eta \mathrm{LC}-\mathrm{MS} / \mathrm{MS}$ system, and a total of $12,685 \mathrm{MS} / \mathrm{MS}$ spectra were obtained. These spectra were searched with VEMS v3.0 (24) and Mascot (31) against a $S$. meliloti 1021 protein sequence database. A total of 751 proteins were identified with a minimum score of 40, and with at least one peptide hit per protein (data not shown). The genomic sequence of $S$. meliloti is predicted to contain 6,294 protein encoding frames (11), thus the proteins identified here account for approximately $12 \%$ of the genome's coding capacity. Amino acid sequences of all proteins identified here were taken to predict their membrane topology using publicly available bioinformatics tools. Proteins having potential trans-membrane domains (TMDs) in either alpha helix or beta barrel segments were defined as membrane proteins in this study. Since there are various methods of predicting alpha helix TMDs using different algorithms three computational methods (TopPred II (7), TMHMM 2.0 (22), and SPOCTOPUS (41)) were used for database searching to obtain accurate results. The TopPred II method is based on two biochemical features of transmembrane segments: hydrophobicity and the inside-positive rule. TMHMM 2.0 is designed to identify alpha helix TMDs, while SPOCTOPUS is an algorithm for combined predictions of signal peptides (SPs) and membrane protein topology. In order to minimize false predictions, only proteins having all predictions agreement were classified as membrane proteins. The transmembrane beta strands were searched by TMBETA-NET. The defined membrane proteins were confirmed by their localization using PSORT and Localizome.

Altogether, the three programs predicted a total of 105 proteins containing transmembrane segments (Supplemental material 1). Thus, these proteins are highly likely to be membrane proteins. The TMDs ranged in number from 1 to 17 (Fig. 1). More than half of the proteins contained 1 to 3 TMDs. The success of the membrane enrichment and separation protocol is reflected by the observation of proteins with high numbers of transmembrane domains (TMDs), such as SMb20291 (17 TMDs by TopPred II and SPOCTOPUS programs, and 15 TMDs by TMHMM 2.0 program), SMc01925 (15 TMDs by TopPred II and SPOCTOPUS programs, and 16 TMDs by TMHMM 2.0 program), and SMa1662 (11 TMDs by TopPred II program, and 12 TMDs by SPOCTOPUS and TMHMM 2.0 program).

Among the 105 membrane proteins, one had been detected in S. meliloti by a proteomic analysis (Supplemental material 1) (9). This is the first comprehensive characterization of the Sinorhizobium sp. BL3 membrane proteome. Comparison of our identified proteins with proteins reported in membrane proteomic analyses $(1,2,9,14,26)$ revealed that our strategy provided the higher possibility of identification rather than either 2D gel or MALDI TOF/TOF.

The classification of 105 membrane proteins based on clusters of orthologous groups of proteins (COGs) revealed 17 groups of major functional categories (Fig. 2). The largest categories were the energy production and conversion (group C) of 16 proteins $(15 \%)$. Several membrane proteins in group $\mathrm{C}$ are responsible for electron transport; for example, SMc00009, SMc00188, SMa0769, SMa1213, SMb21368, 


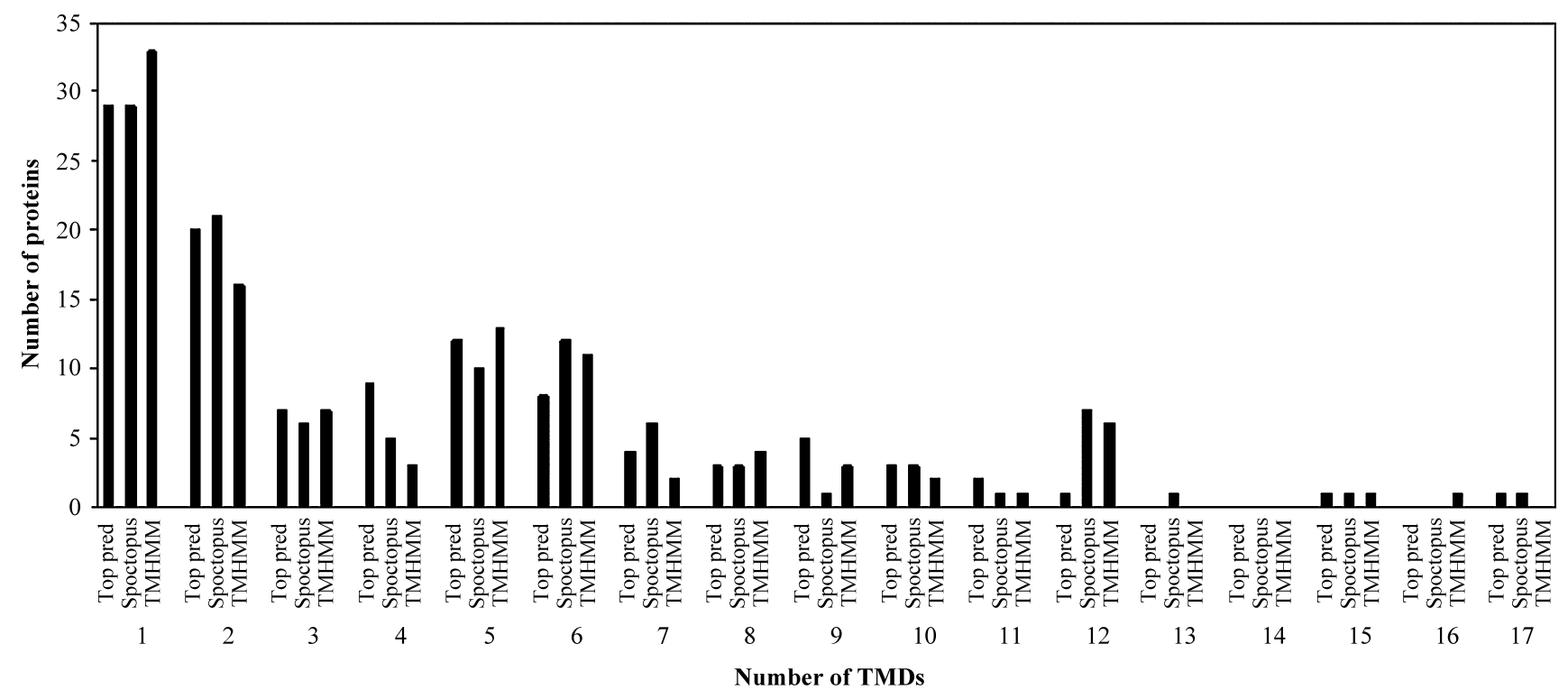

Fig. 1. Predicted transmembrane domains of identified membrane proteins. The number of proteins with different numbers of transmembrane domains, predicted from TopPred, SPOCTOPUS, and TMHMM 2.0 programs.

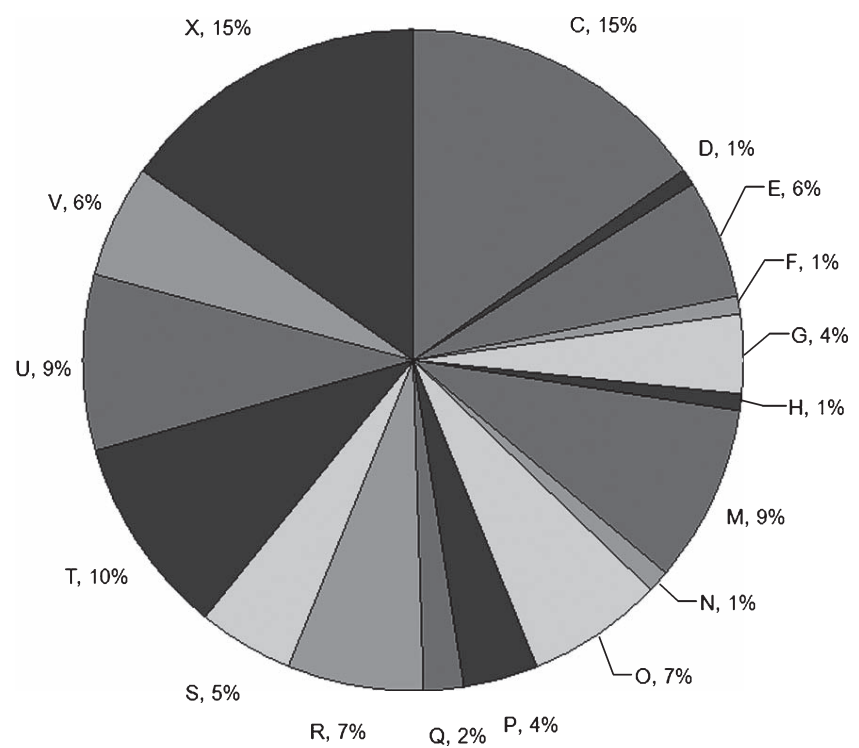

Fig. 2. Pie charts representing percentage of functional category distribution of the 372 identified membrane proteins identified by 2D$\eta \mathrm{LC}-\mathrm{MS} / \mathrm{MS}$. All identified proteins are presented in supplementary material; C: Energy production and conversion; D: Cell cycle control, mitosis and meiosis; E: Amino acid transport and metabolism; $\mathrm{F}$ : Nucleotide transport and metabolism; G: Carbohydrate transport and metabolism; H: Coenzyme transport and metabolism; M: Cell wall/ membrane biogenesis; N: Cell motility; O: Posttranslational modification, protein turnover, chaperones; P: Inorganic ion transport and metabolism; Q: Secondary metabolites biosynthesis, transport and catabolism; R: General function prediction only; S: Function unknown; $\mathrm{T}$ : Signal transduction mechanisms; U: Intracellular trafficking and secretion; V: Defense mechanisms; X: Not in Clusters of Orthologous Groups of proteins (COGs).

and SMc00010. Identification of energy production and conversion enzymes posed a high confidence in their expression in the membrane region. SMc02464 (probable succinate dehydrogenase membrane anchor subunit protein) is relevant to the TCA cycle. The subunits of energy production proteins have been determined to be part of the membrane proteome in many organisms (14).

Large number of membrane proteins $(15 \%)$ also fall into group $\mathrm{X}$, which has not yet been assigned a function in COGs. However, this group contains many interesting proteins which may play an important role in salt stress adaptation, e.g., SMb20813, SMc01492 and SMc00975.

Several proteins $(6 \%)$ belong to a cluster of genes involved in amino acid transport and metabolism (group E). SMb20477 (dipeptide ABC transporter permease protein), SMa0300 (ABC transporter/permease), SMc02738 (putative glycine betaine transport system permease $\mathrm{ABC}$ transporter protein), and SMc02119 (probable general L-amino acid transport permease $\mathrm{ABC}$ transporter protein). These proteins are a reflection of the key roles of membrane proteins in the life cycles of Sinorhizobium sp. BL3 to environmental adaptation, which requires transportation of compatible solutes from the environment to maintain cell integrity. This strategy provides protection from extinction in changing environments for a large variety of microorganisms, which rely exclusively on organic compatible solutes for osmoadaptation (8).

It is worth noting that 7 proteins fall into group $\mathrm{O}$ of posttranslational modification, protein turnover, and chaperones. Among these groups of protein, a group of membrane protease proteins (SMc01135, SMc01440, SMc01441, and SMc04459) were identified. Proteases are important components of complex regulatory networks to cope with environmental stress in many organisms $(39,42)$. SMc04459 (FtsH) has previously been identified in nodule bacteria (9). This protein is required for growth and responsible for the rapid turnover of key proteins by progressively degrading both cytoplasmic and membrane proteins in E. coli (18).

\section{Comparative analysis of membrane proteins under salt stress conditions by peptide derivatization}

In an attempt to determine the appearance of differentially 
Table 1. Membrane proteomic analysis of Sinorhizobium sp. BL3 under salt stress conditions

\begin{tabular}{|c|c|c|c|c|c|c|c|c|c|}
\hline \multirow{2}{*}{ gene ID $^{\mathrm{a}}$} & \multirow{2}{*}{ Score $^{b}$} & \multicolumn{2}{|c|}{$0.4 \mathrm{M} \mathrm{NaCl} 1 \mathrm{~h}$} & \multicolumn{2}{|c|}{$0.4 \mathrm{M} \mathrm{NaCl} 6 \mathrm{~h}$} & \multicolumn{2}{|c|}{$0.5 \mathrm{M} \mathrm{NaCl} 1 \mathrm{~h}}$. & \multicolumn{2}{|c|}{$0.5 \mathrm{M} \mathrm{NaCl} 6 \mathrm{~h}$} \\
\hline & & $E L^{c}$ & $\mathrm{P}^{\mathrm{d}}$ & $E L^{c}$ & $\mathrm{P}^{\mathrm{d}}$ & $E L^{c}$ & $\mathrm{P}^{\mathrm{d}}$ & $E L^{c}$ & $\mathrm{P}^{\mathrm{d}}$ \\
\hline SMb20181 & 55 & $1.99 \pm 0.002$ & 2 & $2.91 \pm 0.000$ & 1 & $1.24 \pm 0.062$ & 3 & $1.84 \pm 0.028$ & 3 \\
\hline SMc04439 & 121 & $1.15 \pm 0.000$ & 1 & $1.52 \pm 0.000$ & 1 & $1.22 \pm 0.000$ & 1 & $2.52 \pm 0.001$ & 2 \\
\hline SMc02502 & 391 & $0.89 \pm 0.013$ & 4 & $0.91 \pm 0.010$ & 3 & $1.36 \pm 0.033$ & 4 & $2.46 \pm 0.053$ & 2 \\
\hline SMc00009 & 515 & $0.97 \pm 0.011$ & 4 & $0.87 \pm 0.017$ & 4 & $1.01 \pm 0.049$ & 7 & $1.63 \pm 0.037$ & 6 \\
\hline SMc03938 & 404 & $0.76 \pm 0.000$ & 1 & $0.97 \pm 0.000$ & 1 & $0.84 \pm 0.076$ & 4 & $3.17 \pm 0.034$ & 3 \\
\hline SMc04459 & 289 & $0.79 \pm 0.000$ & 2 & $1.72 \pm 0.000$ & 1 & $1.05 \pm 0.011$ & 6 & $2.7 \pm 0.046$ & 7 \\
\hline SMc01948 & 349 & $0.99 \pm 0.000$ & 1 & $1.55 \pm 0.000$ & 1 & $1.28 \pm 0.012$ & 5 & $2.84 \pm 0.010$ & 3 \\
\hline SMc01499 & 351 & $0.89 \pm 0.019$ & 2 & $1.06 \pm 0.001$ & 4 & $1.18 \pm 0.031$ & 4 & $1.57 \pm 0.052$ & 3 \\
\hline SMc00868 & 164 & $0.98 \pm 0.047$ & 2 & $1.05 \pm 0.000$ & 1 & $0.91 \pm 0.043$ & 2 & $0.97 \pm 0.025$ & 2 \\
\hline SMc02942 & 177 & $1.14 \pm 0.000$ & 1 & $1.04 \pm 0.000$ & 1 & $1.09 \pm 0.030$ & 2 & $1.07 \pm 0.017$ & 4 \\
\hline
\end{tabular}

${ }^{\mathrm{a}}$ Gene ID achieved from Mascot search (40) against a $S$. meliloti 1021 protein sequence database (http://genome.kazusa.or.jp/rhizobase/Sinorhizobium /genes.faa): SMb20181, ABC transporter periplasmic solute-binding protein; SMc04439, ABC transporter glycine betaine transport ATP-binding protein; SMc02502, ATP synthase epsilon chain; SMc00009, Cytochrome C oxidase subunit II; SMc03938, Transmembrane NAD(P) transhydrogenase subunit $\beta$; SMc04459, Transmembrane metalloprotease; SMc01948, ABC transporter high-affinity branched-chain amino acid transport; SMc01499, ABC Transporter ATP-binding transport; SMc00868, ATP synthase subunit B; SMc02942, peptidoglcan-associated lipoprotein precursor.

${ }^{\mathrm{b}}$ Mascot score $(P<0.05)$ from Mascot v. 2.0 (Matrix Sciences, London, UK).

${ }^{\mathrm{c}}$ Expression level (fold changes).

${ }^{\mathrm{d}}$ Number of identified peptides used for quantization by VEMS v3.0.

displayed proteins responding to different salt shock periods of Sinorhizobium sp. BL3, the comparative method using stable isotope labeling of peptides was conducted for the $\eta \mathrm{LC}-\mathrm{MS} / \mathrm{MS}$ run. In this study, the label chosen for quantification was 2-methoxy-4,5-dihydro- $1 H$-imidazole ('Mass Tag'), which is an epsilon-amine specific derivatization reagent, hence only lysine residues are labeled. The labeling strategy provides a mass difference of 4 daltons between the heavy and light versions of the reagent, allowing quantitation of the same peptide in different experimental conditions in one measurement (32). This approach is suitable for comparative analyses, providing reproducible coverage, since the identified peptides are not limited and all the ions are fragmented in each run. Each experimental condition (4 salt stress conditions) was run in two technical replicates with one dimensional $\eta \mathrm{LC}-\mathrm{MS} / \mathrm{MS}$.

A total of $11,341 \mathrm{MS} / \mathrm{MS}$ spectra were obtained from four experimental conditions with two replicates of cell preparation (exposed Sinorhizobium sp. BL3 into $0.4 \mathrm{M}$ and $0.5 \mathrm{M}$ $\mathrm{NaCl}$ for 1 and $6 \mathrm{~h}$ ). The mass spectrometric data were searched against protein sequences database of $S$. meliloti 1021, eluting 258 confident protein matches $(P<0.05)$. Since approximately half of the identified peptides do not contain lysine residues in the sequence, 138 membrane proteins were potentially quantified. To determine a significant threshold for these changes, we considered any protein whose expression level changed by at least 1.5 fold in either direction (means quantitation value over $60 \%$ or less than $40 \%$ ), to be of potential interest. Moreover, only proteins which exist in all 4 experimental conditions were taken into consideration. Based on these criteria, we succeeded in the identification of 8 membrane proteins of Sinorhizobium sp. BL3 expressed in response to all salt stress conditions (Table 1). Not only was the concentration of membrane proteins derived from each culture preparation analyzed by using the Bradford method and were equal amounts of digested membrane proteins used for chemical derivertization, but also the constant proteins in cellular levels were used as an internal control to normalize the stressed cells and non-stressed of each stress condition. Thus, these criteria would confide our methodology in term of quantitation analysis. These proteins were SMc00868 (ATP synthase subunit B) and SMc02942 (peptidoglycanassociated lipoprotein precursor) and constantly expressed (the expression level changed less than 1.5 folds) in all 4 experimental conditions (Table 1). Therefore, the amounts of derivatized proteins between salt stressed cells and nonstressed cells were possibly close proportion in each stress condition. Nevertheless, the fold changes analysis of protein display only the trend of expression level in each condition.

The concentration and time dependent experiments provided a clue in complicated networks of these membrane proteins that bacterial cells used to promote their adaptation in severe salt stress conditions. It is clear from this finding that the quantitative proteomics approaches using Mass Tag labeling after sample preparation was successfully performed, allowing flexible experimental designs to be conducted. This present work has not yet been attempted on a large scale of quantitative differential expression of membrane proteins using the multidimensional $\eta \mathrm{LC}-\mathrm{MS} / \mathrm{MS}$, but we presented the possibility of using the membrane protein isotopic labeling technique for quantitative analysis. Future experiment is needed to demonstrate the precise action of salt on Sinorhizobium sp. BL3 membrane, thus the actual mechanisms of bacterial membrane against salt stress will be explored.

\section{Acknowledgements}

This project was supported by the ASEM-DUO Denmark program for exchange of scientists (O.N.J., M.Y., and W.T.) between the University of Southern Denmark and Suranaree University of Technology, Thailand. Additional support was provided by a grant from the Danish Natural Sciences Research Council and Suranaree University of Technology. 


\section{References}

1. Aivaliotis, M., C. Corvey, I. Tsirogianni, M. Karas, and G. Tsiotis 2004. Membrane proteome analysis of the green-sulfur bacterium Chlorobium tepidum. Electrophoresis 25:3468-3474.

2. Angelis, D.M., and M. Gobbetti. 2004. Environmental stress responses in Lactobacillus: a review. Proteomics 4:106-122.

3. Bendtsen, J.D., H. Nielsen, G. von Heijne, and S. Brunak. 2004. Improved prediction of signal peptides: SignalP 3.0. J. Mol. Biol. 340:783-795.

4. Blonder, J., M.B. Goshe, W. Xiao, D.G. Camp, M. Wingerd, R.W. Davis, and R.D. Smith. 2004. Global analysis of the membrane subproteome of Pseudomonas aeruginosa using liquid chromatographytandem mass spectrometry. J. Proteome Res. 3:434-444.

5. Boscari, A., K. Mandon, L. Dupont, M.C. Poggi, and D. Le Rudulier. 2002. BetS is a major glycine betaine/proline betaine transporter required for early osmotic adjustment in Sinorhizobium meliloti. J. Bacteriol. 184:2654-2663.

6. Bradford, M.M. 1976. A rapid and sensitive method for the quantitation of microgram quantities of protein utilizing the principle of protein-dye binding. Anal. Biochem. 72:248-254.

7. Claros, M.G., and G. von Heijne. 1994. TopPred II: An improved software for membrane protein structure predictions. CABIOS 10:685-686.

8. Da Costa, M.S., H. Santos, and E.A. Galinski. 1998. An overview of the role and diversity of compatible solutes in Bacteria and Archaea. Adv. Biochem. Eng. Biotechnol. 61:117-153.

9. Djordjevic, M.A., H.C. Chen, S. Natera, G. Van Noorden, C. Menzel, S. Taylor, C. Renard, O. Geiger, and G.F. Weiller. 2003. A global analysis of protein expression profiles in Sinorhizobium meliloti: discovery of new genes for nodule occupancy and stress adaptation. Mol. Plant Microbe Interact. 16:508-524.

10. Dmitrieva, N.I., and M.B. Burg. 2004. Living with DNA breaks is an everyday reality for cells adapted to high $\mathrm{NaCl}$. Cell Cycle 3:561563

11. Galibert, F., T.M. Finan, S.R. Long, et al. 2001. The composite genome of the legume symbiont Sinorhizobium meliloti. Science 293:668-672.

12. Gardy, J.L., M.R. Laird, F. Chen, S. Rey, C.J. Walsh, M. Ester, and F.S.L. Brinkman. 2005. PSORTb v.2.0: expanded prediction of bacterial protein subcellular localization and insights gained from comparative proteome analysis. Bioinformatics 21:617-623.

13. Gobom, J., E. Nordhoff, E. Mirgorodskaya, R. Ekman, and P. Roepstorff. 1999. Sample purification and preparation technique based on nano-scale reversed-phase columns for the sensitive analysis of complex peptide mixtures by matrix-assisted laser desorption/ ionization mass spectrometry. J. Mass Spectrom. 34:105-116.

14. Gu, S., J. Chen, K.M. Dobos, E.M. Bradbury, J.T. Belisle, and X. Chan. 2003. Molecular and cellular proteomic profiling of membrane constituents of a Mycobacterium tuberculosis strain. Mol. Cell. Proteomics 2:1284-1296.

15. Gygi, S.P., Y. Rochon, B.R. Franza, and R. Aebersold. 1999. Correlation between protein and mRNA abundance in yeast. Mol. Cell. Biol. 19:1720-1730.

16. Hatzimanikatis, V., and K.H. Lee. 1999. Dynamical analysis of gene networks requires both mRNA and protein expression information. Metab. Eng. 1:275-281.

17. Howieson, J.G. 1985. Use of an organic buffer for the selection of the acid tolerant Rhizobium meliloti strains. Plant Soil 88:367-376.

18. Jayasekera, M.M., S.K. Foltin, E.R. Olson, and T.P. Holler. 2000. Escherichia coli requires the protease activity of $\mathrm{FtsH}$ for growth. Arch. Biochem. Biophys. 380:103-107.

19. Klebba, P.E., and S.M. Newton. 1998. Mechanisms of solute transport through outer membrane porins: burning down the house. Curr. Opin. Microbiol. 1:238-247.

20. Klein, Ch., C. Garcia-Rizo, B. Bisle, B. Scheffer, H. Zischka, F. Pfeiffer, F. Siedler, and D. Oesterhelt. 2005. The membrane proteome of Halobacterium salinarum. Proteomics 5:180-197.

21. Koebnik, R. 1999. Structural and functional roles of the surfaceexposed loops of the beta-barrel membrane protein OmpA from Escherichia coli. J. Bacteriol. 181:3688-3694.

22. Krogh, A., B. Larsson, G. von Heijne, and E.L.L. Sonnhammer. 2001. Predicting transmembrane protein topology with a hidden Markov model: Application to complete genomes. J. Mol. Biol. 305:567-580.

23. Lee, S., B. Lee, I. Jang, S. Kim, and J. Bhak. 2006. Localizome: a server for identifying transmembrane topologies and TM helices of eukaryotic proteins utilizing domain information. Nucleic Acids Res. 34:W99-W103.

24. Matthiesen, R., J. Bunkenborg, A. Stensballe, O.N. Jensen, K.G. Welinder, and G. Bauw. 2004. Database-independent, databasedependent, and extended interpretation of peptide mass spectra in VEMS V2.0. Proteomics 4:2583-2593.

25. Mawuenyega, K.G., C.V. Forst, K.M. Dobos, J.T. Belisle, J. Chen, E.M. Bradbury, A.R.M. Bradbury, and X. Chen. 2005. Mycobacterium tuberculosis functional network analysis by global subcellular protein profiling. Mol. Biol. Cell 16:396-404.

26. Molloy, M.P. 2000. Two-dimensional electrophoresis of membrane proteins using immobilized $\mathrm{pH}$ gradients. Anal. Biochem. 280:1-10.

27. Molloy, M.P., B.R. Herbert, M.B. Slade, T. Rabilloud, A.S. Nouwens, K.L. Williams, and A.A. Gooley. 2000. Proteomic analysis of the Escherichia coli outer membrane. Eur. J. Biochem. 267:28712881 .

28. Molloy, M.P., N.D. Phadke, J.R. Maddock, and P.C. Andrews. 2001. Two-dimensional electrophoresis and peptide mass fingerprinting of bacterial outer membrane proteins. Electrophoresis 22:1686-1696.

29. Nogales, J., R. Campos, H. Ben Abdelkhalek, J. Olivares, C. Lluch, and J. Sanjuan. 2002. Rhizobium tropici genes involved in free-living salt tolerance are required for the establishment of efficient nitrogenfixing symbiosis with Phaseolus vulgaris. Mol. Plant Microbe Interact. 15:225-232.

30. Payakapong, W., P. Tittabutr, N. Teaumroong, N. Boonkerd, P.W. Singleton, and D. Borthakur. 2006. Identification of two clusters of genes involved in salt tolerance in Sinorhizobium sp. strain BL3. Symbiosis 41:47-51.

31. Perkins, D.N., D.J. Pappin, D.M. Creasy, and J.S. Cottrell. 1999. Probability-based protein identification by searching sequence databases using mass spectrometry data. Electrophoresis 20:35513567

32. Peters, E.C., D.M. Horn, D.C. Tully, and A. Brock. 2001. A novel multifunctional labeling reagent for enhanced protein characterization with mass spectrometry. Rapid Comm. Mass Spectrom. 15:23872392.

33. Phillips, R., T. Ursell, P. Wiggins, and P. Sens. 2009. Emerging roles for lipids in shaping membrane-protein function. Nature 459:379385.

34. Rappsilber, J., Y. Ishihama, and M. Mann. 2003. Stop and go extraction tips for matrix-assisted laser desorption/ionization, nanoelectrospray, and LC/MS sample pretreatment in proteomics. Anal. Chem. 75:663-670.

35. Ruberg, S., Z.X. Tian, E. Krol, B. Linke, F. Meyer, Y. Wang, A. Puhler, S. Weidner, and A. Becker. 2003. Construction and validation of a Sinorhizobium meliloti whole genome DNA microarray: genomewide profiling of osmoadaptive gene expression. J. Biotechnol. 106:255-268.

36. Rudge, S.A., V.A. Sciorra, M. Iwamoto, C. Zhou, T. Strahl, A.J. Morris, J. Thorner, and J. Engebrecht. 2004. Roles of phosphoinositides and of Spo14p (phospholipase D)-generated phosphatidic acid during yeast sporulation. Mol. Biol. Cell. 15:207-218.

37. Santoni, V., M.P. Molloy, and T. Rabillound. 2000. Membrane proteins and proteomics: un amour impossible? Electrophoresis 21:1054-1070.

38. Talibart, R., H. Jebbar, K. Gouffi, V. Pichereau, G. Gouesbet, C. Blanco, T. Bernard, and J.A. Pocord. 1997. Transient accumulation of glycine and dynamics of endogenous osmolytes in salt stresses cultures of Sinorhizobium meliloti. Appl. Environ. Microbiol. 63:4657-4663.

39. Tomoyasu, T., J. Gamer, B. Bukau, et al. 1995. Escherichia coli FtsH is a membrane-bound, ATP-dependent protease which degrades the heat-shock transcription factor sigma 32. EMBO J. 14:2551-2560.

40. Vicent, J.M. 1970. A manual for the practical study of root-nodule bacteria, p. 164. In International Biological Programme (IBP) Handbook No. 15. Blackwell Scientific Publications, London, UK.

41. Viklund, H., A. Bernsel, M. Skwark, and A. Elofsson. 2008. SPOCTOPUS: a combined predictor of signal peptides and membrane protein topology. Bioinformatics 24:2928-2929.

42. Wagner, K., J. Schilling, S. Fälker, M.A. Schmidt, and G. Heusipp. 2009. A regulatory network controls expression of the in vivoexpressed HreP protease of Yersinia enterocolitica. J. Bacteriol. 191:1666-1676.

43. Washburn, M.P., D. Wolters, and J.R. Yates III. 2001. Large-scale analysis of the yeast proteome via multidimensional protein identification technology. Nat. Biotech. 19:242-247. 